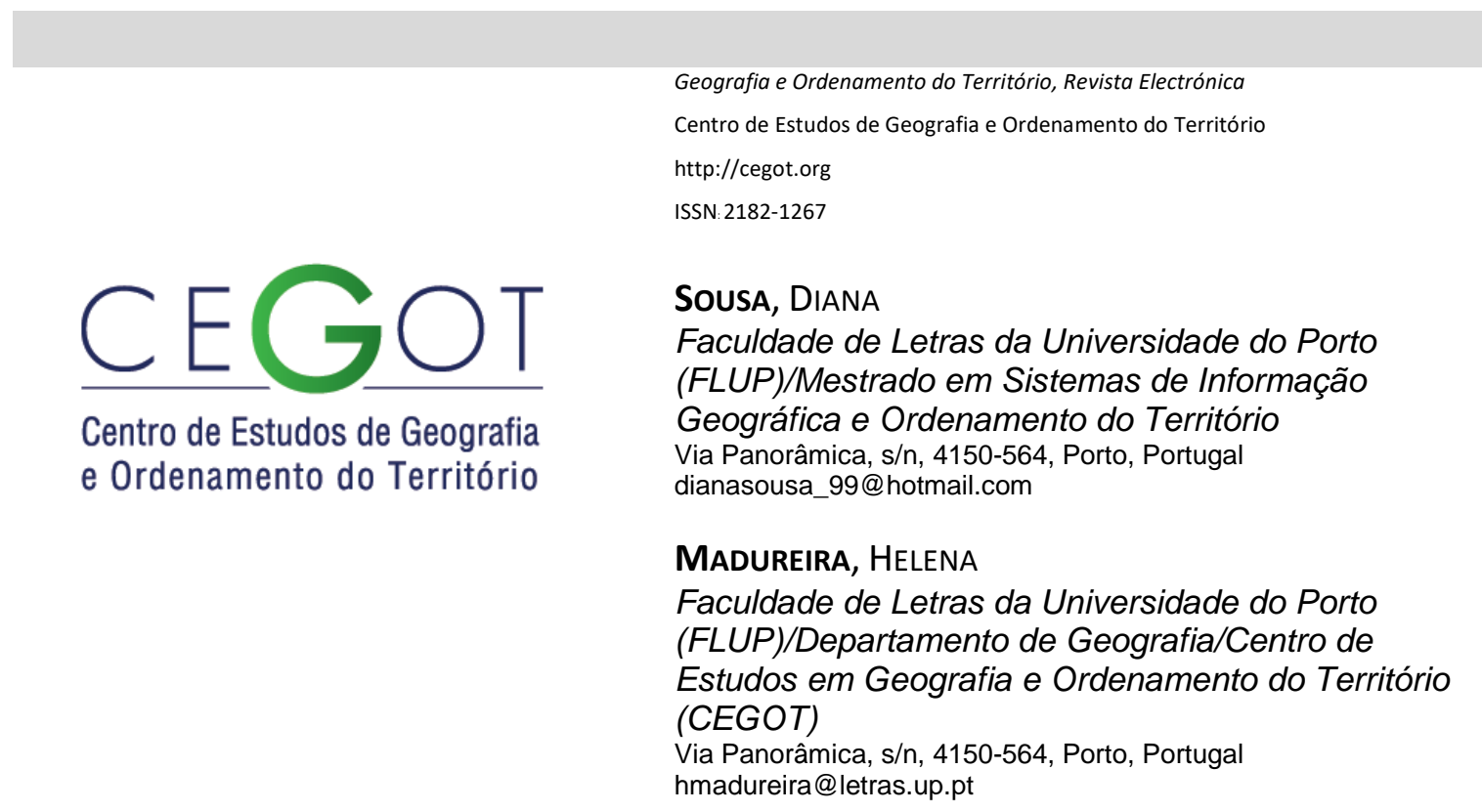

\title{
Padrões territoriais da agricultura urbana na cidade do Porto
}

Territorial patterns of urban agriculture in Porto

Referência: Sousa, Diana; Madureira, Helena (2017). Padrões territoriais da agricultura urbana na cidade do Porto. Revista de Geografia e Ordenamento do Território (GOT), n.o 11 (junho). Centro de Estudos de Geografia e Ordenamento do Território, p. 309-325, dx.doi.org/10.17127/got/2017.11.014

\section{RESUMO}

A agricultura urbana tem vindo a despertar um interesse crescente ao nível académico, institucional e da sociedade em geral e encontra-se em expansão um pouco por todo o mundo. Resulta de práticas espontâneas, mas também cada vez mais de políticas públicas, que necessitam de ser informadas sobre as condições socioterritorais que the estão subjacentes. Neste trabalho identificamos e categorizamos as áreas cultivadas na área central da cidade do Porto e analisamos os seus padrões territoriais. Adicionalmente, exploramos e discutimos alguns critérios de seleção de áreas prioritárias para a expansão da agricultura urbana.

Palavras-chave: Agricultura urbana; Hortas Urbanas; Porto

\section{ABSTRACT}

Urban agriculture has been awakening a growing interest from scholars, policy makers and society in general, and it is expanding through the world. It is a result of spontaneous practices in cities but also of public policies, which need to be informed about its socioterritorial context. In this work, we identify and classify the urban agriculture areas in the central area of the city of Porto and we analyses its territorial patterns. In addition, we explore and discuss some criteria for the selection of urban agriculture expansion areas. 
Keywords: Urban agriculture; Urban garden; Porto

\section{Introdução}

A agricultura urbana, entendida genericamente como a atividade que engloba o cultivo de vegetais e a criação de animais nas cidades, tem suscitado um crescente interesse nos últimos anos. Estima-se que cerca de 800 milhões de pessoas por todo o mundo estejam envolvidas na agricultura urbana, produzindo cerca de $15 \%$ dos alimentos do mundo (predominantemente fruta, vegetais, lacticínios e pequenos animais) (FAO et al. 2014). Contudo, como discute Hamilton et al. (2013), a situação atual da agricultura urbana no mundo é ainda pouco conhecida, sendo difícil precisar ou validar estes valores.

O termo agricultura urbana é uma designação genérica utilizada para referenciar uma grande variedade condições de produção de bens alimentares nas cidades (Drescher et al. 2006; Marques 2015). De facto, as áreas de agricultura urbana apresentam caraterísticas bem diferenciadas, de acordo com a sua localização, tamanho, escala, técnicas de produção e finalidade dos produtos (Hodgson et al. 2011). Por exemplo a agricultura urbana pode ser intraurbana ou periurbana, implantar-se em solos privados ou públicos; pode ter como objetivo o consumo pessoal ou a comercialização, ou ainda ter fins pedagógicos ou terapêuticos; pode desenvolver-se em grandes parcelas contíguas de solo, em pequenas parcelas não contíguas ou ainda em telhados, varandas ou alpendres. E pode servir-se de diferentes técnicas de produção, a hidroponia, a aquaponia ou a permacultura (Hodgson, Campbell e Bailkey 2011).

Nos variados estudos e publicações que têm vindo a constatar e a sublinhar este renascimento da agricultura urbana, detetam-se um conjunto intricado de fatores justificativos, como a crescente sensibilização para as problemáticas ambientais, a consciencialização da importância da segurança alimentar e nutricional, ou ainda o aumento da pobreza e das desigualdades sociais nas cidades, com inerente dificuldade de acesso a bens alimentares. 
Na realidade, as razões para a persistência ou incremento de práticas agrícolas na cidade são muito diferenciadas de acordo com o contexto territorial. Enquanto nos países em desenvolvimento a prática da agricultura urbana tem persistido ao longo dos anos sobretudo por razões de subsistência alimentar, nos países desenvolvidos um complexo leque de razões de ordem ambiental, social, e económica tem contribuído para um recente renascimento da atividade (Mok et al. 2014).

A consciencialização ambiental de crescentes margens de população sobre os benefícios associados à agricultura urbana será um dos fatores explicativos do renascimento da atividade agrícola em muitas cidades europeias e norte-americanas. De facto, a produção local é vista como um meio eficaz para reduzir os impactes ambientais da produção alimentar, e simultaneamente contribuir para outros benefícios ambientais. Numa recente publicação Goldstein et al. (2016) sintetizaram os benefícios ambientais da agricultura urbana em três principais categorias: i) maior eficiência nas cadeias de consumo, designadamente pela redução das distâncias entre produção e consumo e impactes ambientais associados; ii) interação com os ciclos urbanos de matéria e energia, contribuindo por exemplo para a regularização dos escoamentos superficiais ou para a mitigação das ilhas de calor urbano; iii) benefícios ambientais 'ex-situ' como por exemplo a presumível diminuição da área cultivada, ou a contribuição para o sequestro de carbono.

Por outro lado, a expansão da agricultura urbana nas cidades do mundo desenvolvido tem vindo a ser associada a fatores tão diversos como a crescente valorização da segurança alimentar, a sua incorporação enquanto atividade de recreio e lazer, o reconhecimento do seu papel na interação social e na educação ambiental, ou ainda a sua valorização como elemento de promoção da paisagem urbana (Pulighe e Lupia 2016). Adicionalmente, é cada vez mais consensual o potencial contributo económico da agricultura urbana para as populações urbanas economicamente mais vulneráveis (Mok, Williamson, Grove, Burry, Barker e Hamilton 2014; Pulighe e Lupia 2016).

A agricultura urbana tem, portanto, um caráter potencialmente multifuncional, já que ultrapassa a mera produção de alimentos, e interage com outras esferas promotoras da qualidade ambiental e da saúde nas cidades. De acordo com Mougeot (2000), a característica mais diferenciadora da agricultura urbana é o facto de esta ser parte 
integrante do sistema ecológico e social urbano. De facto, a agricultura urbana estimula a economia local com a venda dos produtos, é influenciada pelas condições locais (políticas, mercados, preços, ...) e gera impactes no próprio sistema local (nas condições ambientais locais, na segurança alimentar, nos níveis de pobreza, na saúde, ...).

Ao mesmo que se multiplicam evidências sobre a expansão da agricultura urbana um pouco por todo o mundo (Marques 2015; Mason e Knowd 2010; Mok, Williamson, Grove, Burry, Barker e Hamilton 2014; Pulighe e Lupia 2016) as políticas urbanas têm crescentemente vindo a incorporar medidas para a sua potenciação, sendo apontadas três principais dimensões de atuação (Van Veenhuizen 2006). A dimensão social está patente nas estratégias orientadas para a subsistência da população urbana economicamente mais vulnerável, focando especialmente a produção de alimentos para consumo doméstico e eventual comercialização de excedentes. Refiram-se ainda as estratégicas vocacionadas para o potencial de inclusão social ou o desenvolvimento comunitário associado à prática agrícola em contexto urbano, designadamente nas hortas sociais e comunitárias. A dimensão ecológica integra as estratégias que visam aproveitar o caráter intrinsecamente multifuncional da agricultura urbana e os vários serviços ecológicos que potencialmente oferece (p.e. compostagem descentralizada e reutilização de resíduos orgânicos e de águas residuais, amenização do clima urbano, gestão da paisagem). Finalmente, a dimensão económica está patente em estratégias para a promoção de uma agricultura urbana orientada para o mercado, envolvendo não só a produção de alimentos, mas também produtos não-alimentares (ervas medicinais e aromáticas, flores, plantas ornamentais).

É crescentemente reconhecido que os processos de tomada de decisão relacionados com o planeamento urbano precisam de dados de alta resolução espacial para estabelecer a relação entre, por um lado, o desempenho socioeconómico do sistema urbano e das suas diferentes subunidades e, por outro lado, os seus impactos ambientais nestas subunidades (Pauleit e Duhme 2000). De facto, apesar de serem cada vez mais consensuais os benefícios associados à agricultura urbana, é importante conhecer o contexto socioterritorial específico em que se desenvolve. Neste sentido, a informação geográfica pode contribuir para o desenvolvimento da agricultura urbana, auxiliando a identificação de potenciais áreas de expansão e permitindo valorizar locais já existentes. Poderá também ser útil para 
identificar e minimizar áreas de risco, designadamente áreas cultivadas em solos contaminados ou irrigadas com água contaminada, ou hortas adjacentes a vias com muito tráfego. Adicionalmente, conhecer a distribuição dos espaços de agricultura urbana na cidade e das caraterísticas sociodemográficas das áreas circundantes pode ajudar os planeadores e demais agentes a direcionar a sua atuação para populações específicas, bem como para condições ambientais particulares (Taylor e Lovell 2012).

Nos últimos anos têm-se vindo a desenvolver projetos de inventariação e referenciação geográfica da agricultura urbana em muitas cidades do mundo. Num recente artigo de revisão Sweeney et al. (2015) frisaram a profusão desses projetos, sintetizando os objetivos, âmbitos e metodologias associados à inventariação e referenciação das áreas de agricultura urbana. Neste trabalho associamo-nos a este crescente movimento, propondo-nos a contribuir para o conhecimento sobre as áreas cultivadas no Porto.

\section{Objetivos e Metodologias}

Este trabalho pretende contribuir para o conhecimento das tipologias e padrões socioterritoriais da agricultura urbana na área central da cidade do Porto - área interior à Via de Cintura Interna ( $\mathrm{VCl}$ - e identificar áreas prioritárias para a sua futura expansão. Este objetivo geral foi detalhado em três objetivos específicos, cujos detalhes e processos metodológicos passamos a apresentar.

\subsection{Identificação e categorização das áreas de agricultura urbana}

Um primeiro objetivo específico consistiu na identificação, vectorização e categorização de todas as áreas cultivadas na área central do Porto.

A identificação das áreas cultivadas foi feita através da interpretação de imagens de satélite de alta resolução disponibilizadas gratuitamente, procedendo-se à sua vectorização manual e integração num sistema de informação geográfica. Trata-se de um procedimento já 
experimentado noutras cidades, designadamente em Chicago (Taylor e Lovell 2012) e Roma (Pulighe e Lupia 2016).

As hortas foram classificadas em três principais categorias, adaptando ao contexto territorial do Porto as classificações desenvolvidas noutros trabalhos similares (Lin et al. 2015; Taylor e Lovell 2012). Na Tabela 1 sintetizam-se as principais caraterísticas de cada uma das categorias. A vectorização manual das hortas urbanas e categorização por tipologia foi continuamente coadjuvada por levantamentos no terreno e entrevistas aos horticultores. Para fins comparativos foram adicionalmente vetorizadas todas as áreas verdes presentes na área de estudo.

\section{Quintais privados (hortas agregadas a edifícios)}

Espaços cultivados em áreas adjacentes aos edifícios para satisfazer diferentes necessidades e funções (ambientais, sociais e económicas) dos proprietários/locatários; podem ter dimensões muito variadas e uma grande diversidade de opções de cultivo

Hortas privadas (hortas desagregadas de edifícios)

Espaços cultivados em áreas autónomas da cidade, não adjacentes aos edifícios, detidos e/ou geridos por particulares para satisfazer diferentes necessidades e funções (ambientais, sociais e económicas); podem ter dimensões muito variadas e uma grande diversidade de opções de

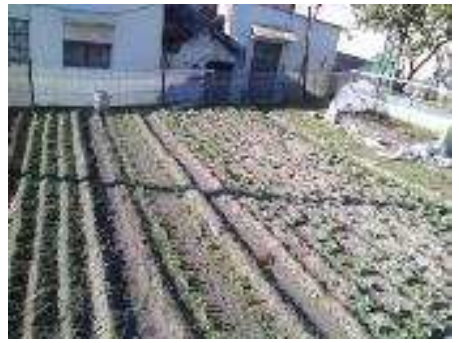
cultivo;

\section{Hortas sociais/comunitárias/pedagógicas}

Hortas sociais /comunitárias: áreas destinadas à horticultura não comercial que são utilizadas por indivíduos ou famílias para seu próprio usufruto. Usualmente as hortas sociais são divididas em talhões e cada uma das parcelas é cultivada individualmente; no caso das hortas comunitárias toda a área é cultivada em grupo;

Hortas pedagógicas: áreas reservadas para a horticultura não comercial com intenção de fomentar a educação ambiental, particularmente da população mais jovem.

Tabela 2 - Principais caraterísticas das três categorias de áreas cultivadas identificadas neste trabalho

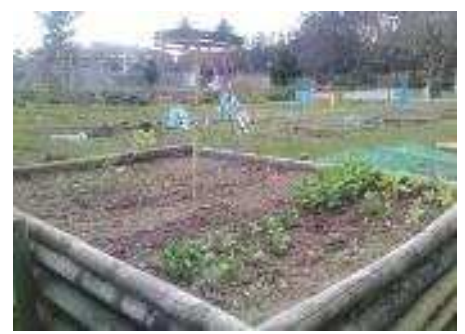




\subsection{Identificação dos padrões socioterritoriais das áreas cultivadas}

Depois de identificadas e categorizadas as hortas urbanas, um segundo objetivo consistiu na identificação dos padrões socioterritoriais das áreas cultivadas na área central do Porto. Pretendeu-se designadamente averiguar as relações entre o padrão espacial das diferentes categorias de áreas cultivadas e alguns indicadores estatísticos evidenciadores da densidade de ocupação humana (densidade populacional e densidade de edifícios) e de vulnerabilidade social (população desempregada e população idosa). Utilizaram-se, para esse efeito, os dados do Instituto Nacional de Estatística, ao nível de subseção estatística, do ano censitário 2011.

Toda a informação foi inserida e trabalhada no sistema de informação geográfica. Para averiguar de relações entre o padrão espacial das áreas cultivadas e as variáveis socioterritoriais, toda a informação foi convertida para raster. As variáveis foram reclassificadas em 5 classes pelo método dos quantis. Finalmente calculou-se o número de pixéis ocupados por áreas cultivadas em cada classe, valores que foram posteriormente convertidos em Km2.

\subsection{Identificação exploratória de áreas prioritárias à expansão da agricultura urbana}

Finalmente, definimos como último objetivo específico estabelecer e testar alguns critérios que permitissem identificar áreas prioritárias à expansão da agricultura urbana na área em estudo. Elegemos cinco critérios exploratórios para a seleção de futuras áreas de cultivo, considerando condições quer de aptidão biofísica quer de potenciação das suas funções sociais: i) áreas verdes, para que o processo de conversão para terreno de cultivo fosse mais exequível; ii) áreas com declives inferiores a 10 graus, para facilitar a sua implementação; iii) exposição orientada a sul, pela estimulação dos processos biológicos; iv) áreas de maior concentração de população idosa (quinto quintil); e v) áreas de concentração de população idosa (quinto quintil), ambos para potenciar as suas funções sociais.

Sublinhamos tratar-se de um processo exploratório, já que outros critérios, como a aptidão e qualidade dos solos, a disponibilidade de água ou a compatibilidade com ocupações/usos 
do solo, poderão no futuro incorporar um projeto mais consistente de seleção de áreas prioritárias à expansão da agricultura urbana

Depois de identificadas as áreas que cumprem simultaneamente os cinco critérios definidos, optámos por aplicar uma área de influência de 100 e 200 metros às subsecções com maior concentração de população idosa e desempregada, já que ainda assim a proximidade se manteria elevada. Finalmente, foram eliminadas as áreas resultantes residuais $(<3 \mathrm{~m} 2)$.

\section{Resultados e Discussão}

\subsection{Padrão espacial da agricultura urbana do Porto}

Os resultados relativos à identificação e caraterização das diferentes categorias de áreas cultivadas estão apresentados na Tabela 2 e revelam numa primeira análise, que as hortas identificadas ocupam uma área total de 0,756 Km2, correspondendo a 4,38\% da área de estudo. O total das áreas verdes apresenta um valor naturalmente mais significativo, representando $11,58 \%$ da área de estudo.

Relativamente à representatividade das diferentes categorias de áreas cultivadas, podemos referir que as hortas agregadas a edifícios são as mais dominantes, representando cerca de 3,34 \% da área de estudo e cerca de $76 \%$ do total das áreas cultivadas identificadas. Seguem-se as hortas desagregadas de edifícios, que ocupam 0,93\% da área de estudo, e representam cerca de $21 \%$ do total de áreas cultivadas. Por fim, as principais hortas pedagógicas/comunitárias, ocupam apenas 0,10\% da área de estudo. 


\begin{tabular}{|c|c|c|}
\hline & Área $(\mathrm{Km} 2)$ & Área (\%) \\
\hline Áreas Verdes & 1,997 & 11,58 \\
\hline Hortas Urbanas & 0,756 & 3,34 \\
\hline Hortas agregadas a edifícios & 0,576 & 0,93 \\
\hline Portas desagregadas de edifícios & 0,161 & 0,10 \\
\hline Área de Estudo & 0,018 & 100 \\
\hline
\end{tabular}

Tabela 3 - Área ocupada pelos diferentes tipos de hortas urbanas

Na Figura 1 podemos observar o padrão espacial definido pelas diferentes categorias de hortas urbanas. As hortas agregadas a edifícios, sendo a mais representada globalmente, encontram-se disseminadas por toda a área de estudo. São genericamente áreas de pequena dimensão, o que é justificado pelo fato de se situarem em terrenos adjacentes às edificações urbanas, normalmente com lotes de também pequena dimensão.

Já as hortas desagregadas de edifícios, ocupam especialmente áreas mais periféricas e adjacentes a infraestruturas rodoviárias e ferroviárias. São genericamente áreas de maior dimensão e ocorrem em contextos de menor densidade de ocupação humana.

As hortas sociais, comunitárias e pedagógicas representam, como referido, apenas $0,10 \%$ da área de estudo. No entanto, merecem atenção pelas suas caraterísticas muito específicas, designadamente, e como já vimos, por promoverem a educação ambiental, promoverem os valores de partilha e solidariedade, e por muitas vezes integrarem projetos de valorização de populações social e economicamente mais vulneráveis. Na área de estudo podemos observar que este tipo de hortas localiza-se maioritariamente no centro histórico da cidade do Porto. Resultaram todas elas de iniciativas da Câmara Municipal do Porto, tendo a maioria sido dinamizadas projeto "Manobras no Porto", promovido pela Porto Lazer e cofinanciado pelo Fundo Europeu de Desenvolvimento Regional (FEDER) (QREN 2007-2013). 


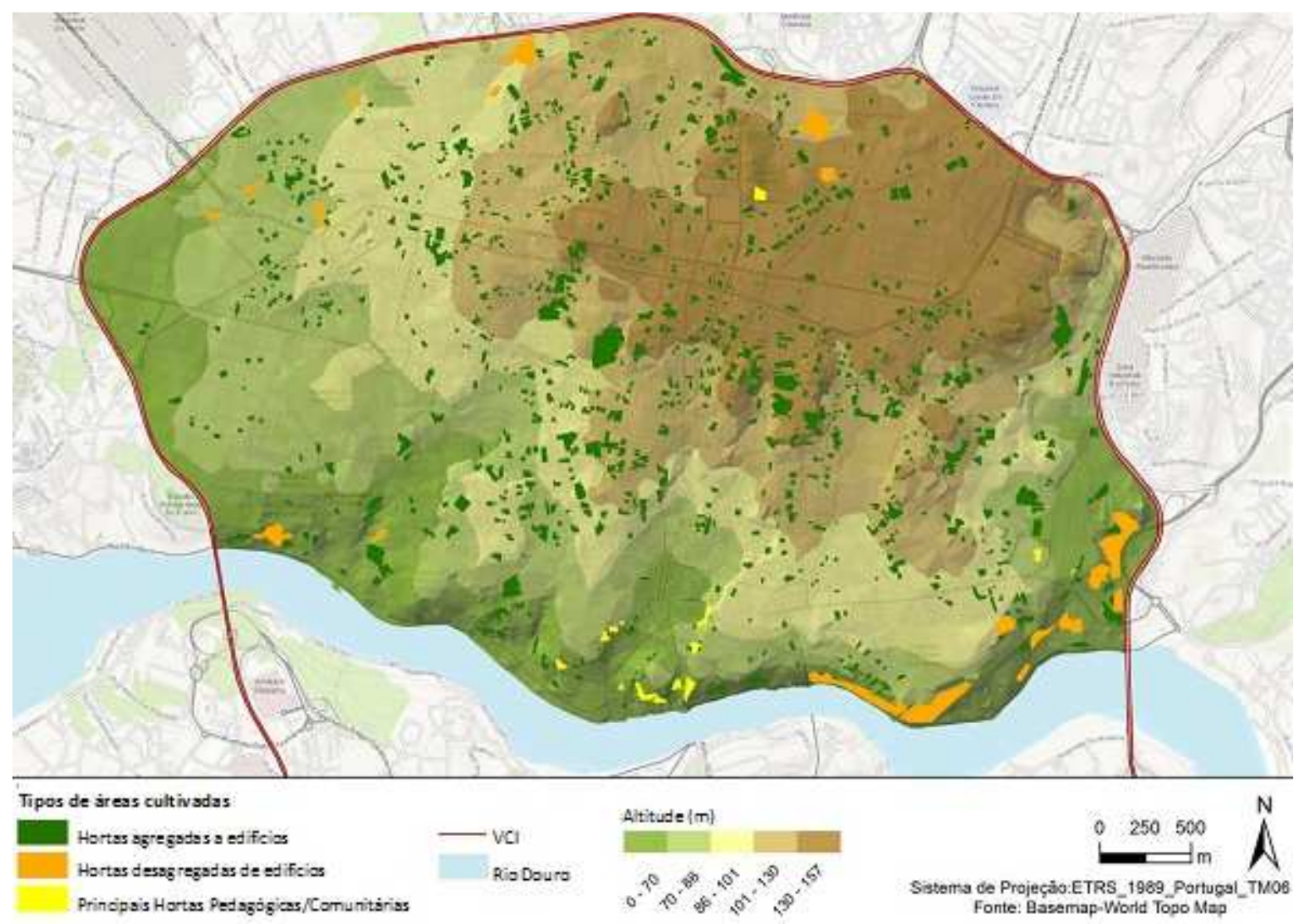

Figura 6 - Distribuição dos diferentes tipos de áreas cultivadas na área de estudo

Os resultados da análise da relação entre os padrões espaciais definidos pelas áreas cultivadas e as caraterísticas socioterritoriais encontram-se sintetizados na Figura 2. Começando pela relação entre o padrão dos diferentes tipos de áreas cultivadas e a densidade de edifícios, e apesar de a relação não ser direta, observa-se que todos os tipos de hortas estão mais representados em contextos intermédios em termos de ocupação por edifícios. A relação espacial entre os diferentes tipos de hortas e a densidade populacional também não é direta, mas distingue-se uma maior prevalência de hortas em contextos de maior densidade populacional. Esta tendência é evidenciada nos três tipos de hortas em análise, mas é especialmente relevante nas hortas pedagógicas e comunitárias. Estes resultados parecem, portanto, apontar para uma tendência de maior expressão de hortas urbanas em contextos de maior densidade populacional e, simultaneamente, onde a densidade de edificado não é excessivamente elevada para permitir a existência de espaço para cultivo. 
Relativamente aos indicadores de vulnerabilidade social, podemos verificar que existe uma maior prevalência de hortas em contextos intermédios em termos de desemprego, sendo de destacar um ligeiro aumento das principais hortas pedagógicas/comunitárias nas subseções com mais desemprego. A relação entre a distribuição da população idosa e das diferentes tipologias de hortas na área em estudo não revela um padrão significativo, refletindo antes uma distribuição equilibrada pelas diferentes classes. Refira-se, no entanto, que para o caso das hortas pedagógicas e comunitárias, existe uma clara tendência para a sua incidência em áreas com maior concentração de idosos.

Os resultados evidenciam, portanto, uma relação ténue entre os padrões espaciais hortas urbanas e os indicadores socioterritoriais, especialmente aqueles indiciadores de vulnerabilidade social.

É, portanto, importante que as políticas de promoção da agricultura urbana tenham em conta critérios de diferente índole. De facto, os espaços de agricultura urbana são multifuncionais proporcionando, como as demais áreas verdes das cidades, benefícios de ordem social, económica e ambiental, e por isso as políticas urbanas devem promover novos espaços de agricultura urbana, privilegiando as áreas que reúnem as condições socioterritoriais mais propícias ao seu desenvolvimento.

Os resultados merecem ser discutidos tendo em vista um futuro desenvolvimento do projeto. De facto, as áreas prioritárias para a expansão da agricultura urbana envolvem contextos muito diferenciados, desde áreas sem uso atual, logradouros, ou jardins públicos (Figura 4). Se em jardins públicos de maior dimensão seria possível considerar a integração de uma área de cultivo, nos mais pequenos, de desenho mais formal, e sobretudo de valor patrimonial, a implementação não seria tão facilmente exequível. 

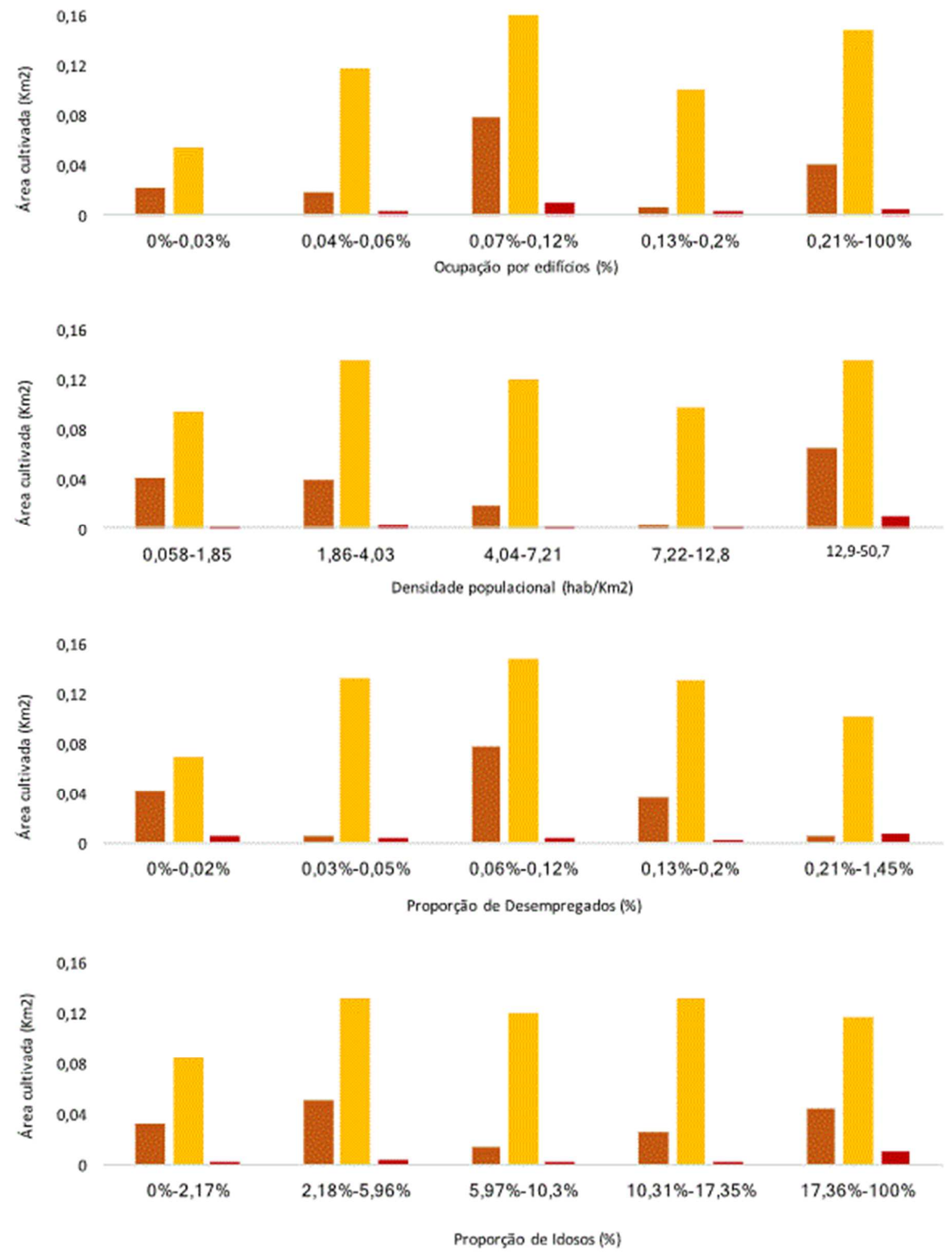

E Horta Desagregada a Habitação = Horta Agregada a Habitaçăo = Principais Hortas Pedagógica Comunitárias

Figura 7 - Relação espacial entre as áreas cultivadas e os indicadores das caraterísticas socioterritoriais da área de estudo 
Os resultados do terceiro objetivo específico deste trabalho espelham, ainda que de modo exploratório, o desígnio de estabelecer áreas prioritárias para a expansão da área cultivada na área central do concelho do Porto, tendo em conta critérios de aptidão biofísica e de potenciação das suas funções sociais (Figura 3).

Espaços Verdes

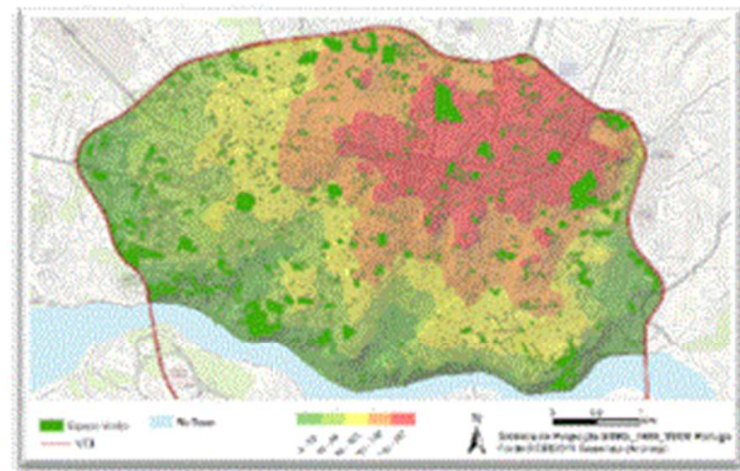

Exposição de vertentes orientada a sul

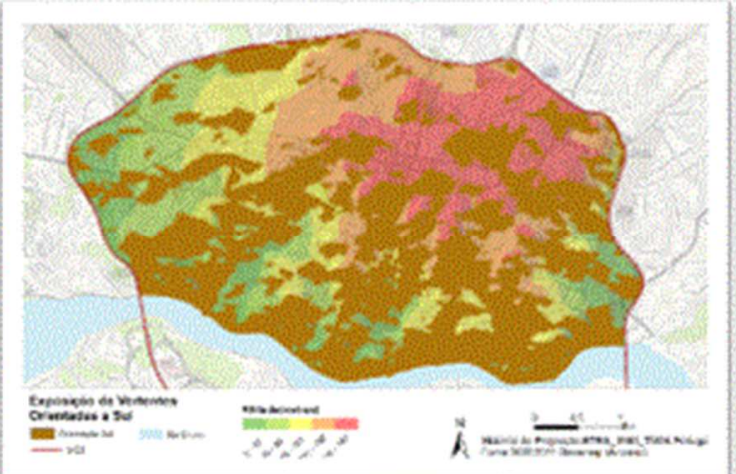

População desempregada (último quintil)

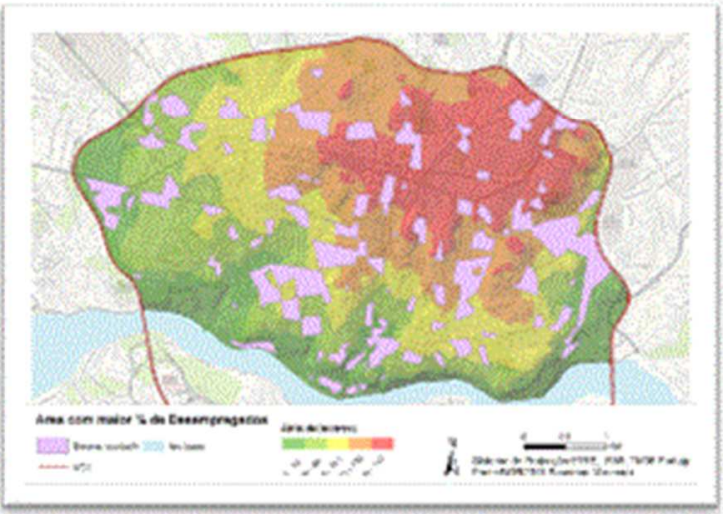

Declives inferiores a 10 graus

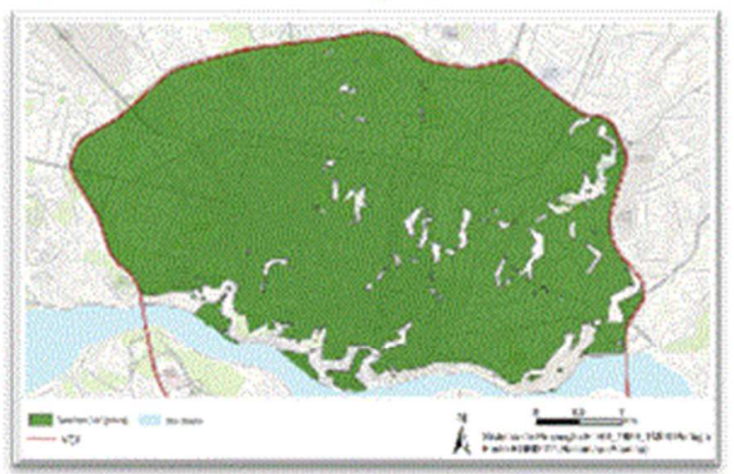

População idosa (último quintil)

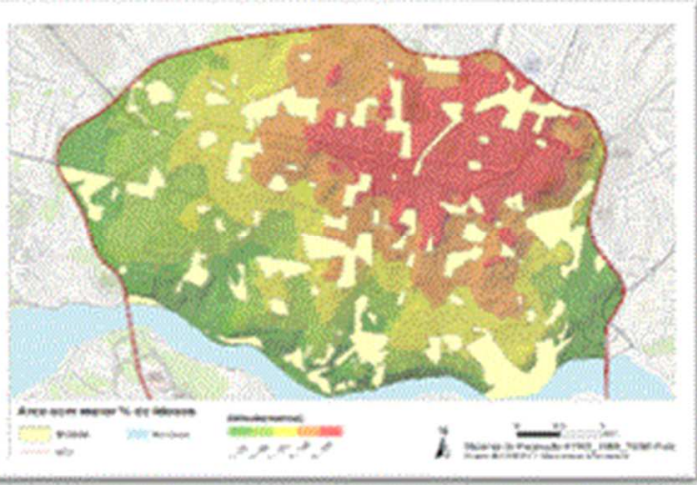

Figura 3- Resultados parciais relativos à aplicação dos cinco critérios para expansão da área cultivada na área central do Porto 
Em síntese, neste estudo exploratório identificaram-se áreas potenciais para a promoção da agricultura urbana de acordo com alguns critérios, que em estudos posteriores deveriam ser melhorados e complementados. Por exemplo, neste caso específico, além da dimensão dos jardins seria importante ponderar os valores patrimoniais, ou seja, considerar que algumas áreas não são passíveis de ser convertidas em áreas cultivadas por constituírem jardins ou espaços verdes com valor estético e cultural.
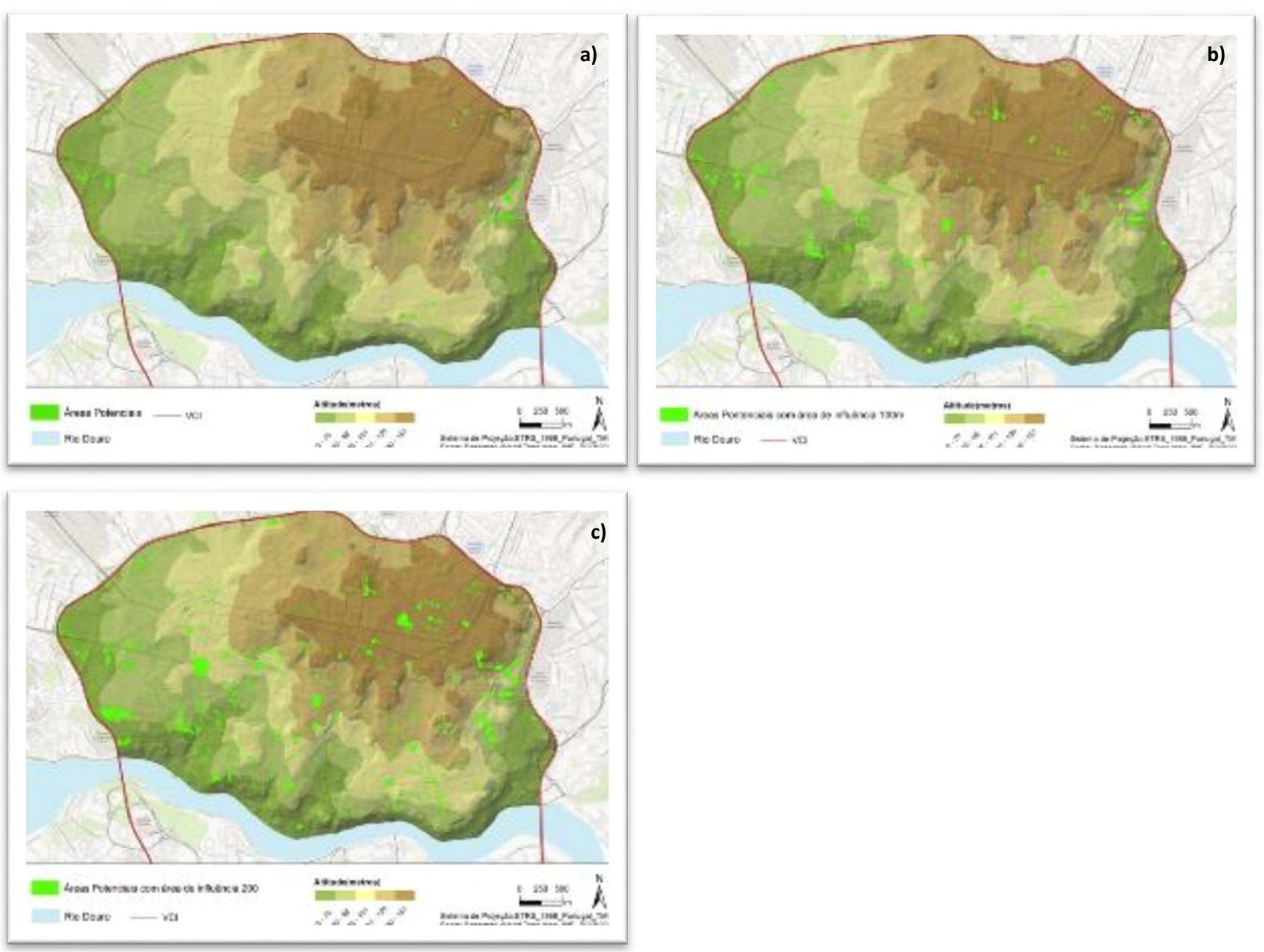

Figura 4- a) Áreas prioritárias para a expansão da agricultura urbana na área central do Porto e considerando b) um 'buffer' de 100 metros; c) um 'buffer' de 200 metros.

Outros critérios que aprimorariam a seleção das áreas prioritárias seriam, como já referimos, a ponderação da proximidade a cursos de água e a aptidão e contaminação dos solos. Ou ainda critérios como o rendimento da população e a proximidade a escolas e a lares de idosos; o primeiro porque permitia identificar franjas populacionais de maior vulnerabilidade socioeconómica; o segundo porque possibilitaria a essas instituições a oportunidade de disporem de uma área apropriada para desenvolver atividades 
relacionadas com a educação ambiental. Finalmente, a seleção das áreas prioritárias deveria ter em conta a sua inserção na estrutura ecológica da cidade e designadamente a sua contribuição para a formalização de corredores ecológicos.

\section{Conclusão}

A agricultura urbana tem vindo crescentemente a concentrar a atenção de cidadãos, decisores políticos e académicos por todo o mundo. A produção de alimentos nas cidades não é necessariamente uma novidade, já que persistem na atualidade muitos exemplos de práticas agrícolas urbanas que remontam há décadas ou séculos. Mas o recente interesse na agricultura urbana envolve uma reinvenção do conceito, sendo-lhe associados múltiplos benefícios e a potencial capacidade de responder aos desafios da sustentabilidade urbana. A atual conceção de agricultura urbana envolve, portanto, o seu caráter potencialmente multifuncional, já que ultrapassa a mera produção de alimentos, e interage com outras esferas promotoras da qualidade ambiental e da saúde nas cidades.

Esta crescente popularidade da agricultura urbana tem tido, contudo, o efeito perverso de potenciar um discurso positivo acrítico e desterritorializado, ignorando quer eventuais efeitos negativos da prática da agricultura urbana, quer as suas múltiplas variantes decorrentes do seu contexto socioterritorial (Prové et al. 2016; Pulighe e Lupia 2016). O conhecimento das condições socioterritorais locais associadas à pratica da agricultura urbana revela-se assim essencial quer para conhecer e compreender as suas atuais dinâmicas, quer para melhor enformar politicas de promoção da agricultura urbana em diferentes cidades.

Este trabalho proporcionou um melhor entendimento do contexto socioterritorial da agricultura urbana na área central do concelho do Porto. Para além de contribuirmos para a identificação das áreas que atualmente são aqui cultivadas, percebemos que o seu padrão espacial não é diretamente explicado por indicadores como a densidade populacional e de edifícios, ou a prevalência de população idosa ou desempregada. Não obstante, e sublinhando a importância das políticas de promoção da agricultura urbana terem em conta 
critérios de aptidão biofísica e de potenciação das suas funções sociais, identificámos, num projeto exploratório, áreas prioritárias para a sua expansão. Os resultados obtidos abrem perspetivas a trabalhos futuros. Por um lado, evidencia-se a necessidade de aprofundar o estudo sobre os contextos associados à agricultura urbana na cidade do Porto, alargando o seu âmbito do ponto de vista conceptual, territorial e metodológico. A aplicação de metodologias qualitativas ou qualitativas que permitam caraterizar os agentes envolvidos na prática da horticultura urbana e evidenciar as condições em que esta é desenvolvida, torna-se, neste âmbito, particularmente relevante. Por outro lado, emerge a importância de desenvolver estudos semelhantes noutras áreas urbanas, nacionais ou internacionais, de modo a alargar a base comparativa e aferir com maior profundidade os fatores sociais, culturais, territoriais, ou mesmo das políticas institucionais mais eficazes na promoção da agricultura em contextos urbanos.

\section{Referências bibliográficas}

DRESCHER, A. W., R. J. HOLMER AND D. L. IAQUINTA. Urban homegardens and allotment gardens for sustainable livelihoods: Management strategies and institutional environments. In B.M. KUMAR AND P.K.R. NAIR eds. Tropical Homegardens: A Time-Tested Example of Sustainable Agroforestry. Dordrecht: Springer Netherlands, 2006, p. 317-338.

FAO, IFAD AND WFP The state of food insecurity in the world 2014. Strengthening the enabling environment for food security and nutrition. Edtion ed. Rome: FAO, 2014.

GOLDSTEIN, B., M. HAUSCHILD, J. FERNÁNDEZ AND M. BIRKVED Urban versus conventional agriculture, taxonomy of resource profiles: a review. Agronomy for Sustainable Development, 2016, 36(1), 9.

HAMILTON, A. J., K. BURRY, H.-F. MOK, S. F. BARKER, et al. Give peas a chance? Urban agriculture in developing countries. A review. Agronomy for Sustainable Development, 2013, 34(1), 45-73.

HODGSON, K., M. C. CAMPBELL AND M. BAILKEY. Investing in Healthy, Sustainable Places through Urban Agriculture. Miami: 2011.

LIN, B. B., S. M. PHILPOTT AND S. JHA The future of urban agriculture and biodiversity-ecosystem services: Challenges and next steps. Basic and Applied Ecology, 2015, 16(3), 189-201.

MARQUES, H. O verde produtivo na AMP no horizonte 2020. GOT : Revista de Geografia e Ordenamento do Território, 2015, (7), 213-229.

MASON, D. AND I. KNOWD The emergence of urban agriculture: Sydney, Australia. International Journal of Agricultural Sustainability, 2010/02/01 2010, 8(1-2), 62-71.

MOK, H.-F., V. G. WILLIAMSON, J. R. GROVE, K. BURRY, et al. Strawberry fields forever? Urban agriculture in developed countries: a review. Agronomy for Sustainable Development, 2014, 34(1), 21-43. 
MOUGEOT, L. J. A. Urban agriculture: definition, presence, potentials and risks. Growing cities, growing food: Urban agriculture on the policy agenda, 2000, 1-42.

PAULEIT, S. AND F. DUHME Assessing the environmental performance of land cover types for urban planning. Landscape and Urban Planning, 2000, 52(1), 1-20.

PROVÉ, C., J. DESSEIN AND M. D. KROM Taking context into account in urban agriculture governance: Case studies of Warsaw (Poland) and Ghent (Belgium). Land Use Policy, 11// 2016, 56, 16-26.

PULIGHE, G. AND F. LUPIA Mapping spatial patterns of urban agriculture in Rome (Italy) using Google Earth and web-mapping services. Land Use Policy, 2016, 59, 49-58.

SWEENEY, G., M. HAND, M. KAISER, J. K. CLARK, et al. The State of Food Mapping. CPL bibliography, 2016/05/01 2015, 31(2), 123-219.

TAYLOR, J. R. AND S. T. LOVELL Mapping public and private spaces of urban agriculture in Chicago through the analysis of high-resolution aerial images in Google Earth. Landscape and Urban Planning, 2012, 108(1), 57-70.

VAN VEENHUIZEN, R. Cities farming for the future: Urban agriculture for green and productive cities. Edtion ed.: IDRC, 2006. ISBN 1552502163. 